\title{
Commentary \\ E-cadherin and loss of heterozygosity at chromosome 16 in breast carcinogenesis: different genetic pathways in ductal and lobular breast cancer?
}

\author{
Anne-Marie Cleton-Jansen \\ Departments of Pathology and Human and Clinical Genetics, Leiden University Medical Centre, Leiden, The Netherlands
}

Correspondence: Anne-Marie Cleton-Jansen, Departments of Pathology and Human and Clinical Genetics, Leiden University Medical Centre, P.O. Box 9600, L1-Q 2300 RC Leiden, The Netherlands. Tel: +31 71 5266515; fax: +31 71 5248158; e-mail A.M.Cleton-Jansen@lumc.nl

Received: 20 September 2001

Breast Cancer Res 2002, 4:5-8

Revisions requested: 2 October 2001

Revisions received: 4 October 2001

Accepted: 4 October 2001

Published: 1 November 2001

(C) 2002 BioMed Central Ltd

(Print ISSN 1465-5411; Online ISSN 1465-542X)

\begin{abstract}
Loss of heterozygosity at the long arm of chromosome 16 is one of the most frequent genetic events in breast cancer. In the search for tumour suppressor genes that are the target of loss of heterozygosity at $16 \mathrm{q}$, the $\mathrm{E}$-cadherin gene $\mathrm{CDH} 1$ was unveiled by the identification of truncating mutations in the retained copy. However, only lobular tumours showed E-cadherin mutations. Whereas investigations are still devoted to finding the target genes in the more frequent ductal breast cancers, other studies suspect the E-cadherin gene to also be the target in this tumour type. The present article discusses the plausibility of those two lines of thought.
\end{abstract}

Keywords: hereditary cancer, loss of heterozygosity, mutation, tumour progression, tumour suppressor genes

\section{Introduction}

The homotypic cellular adhesion molecule E-cadherin is one of the most vital components in the cell. It is implicated as a key player in different cellular processes including development, morphology, polarity, migration and tissue integrity [1]. E-cadherin is a glycoprotein with an extracellular domain that interacts with E-cadherin molecules on adjacent cells, thereby establishing adhesion between epithelial cells. The intracellular domain is associated with a complex of proteins called catenins, which anchor E-cadherin to the actin cytoskeleton.

In various carcinomas, plasma membrane associated E-cadherin protein expression is decreased or even absent. There is transcriptional regulation of this molecule for which a number of factors have been implicated, including promotor hypermethylation [2,3], and several proteins that regulate E-cadherin transcription, especially Snail-1 [4], SIP-1 [5] and integrin-linked kinase [6]. Muta- tional inactivation of the $\mathrm{E}$-cadherin gene $\mathrm{CDH} 1$ has been reported in diffuse gastric cancer and lobular breast cancer [7]. Both these tumour types have a characteristic diffuse growth pattern with loss of cellular coherence that is in accordance with the adhesion function of the absent E-cadherin protein.

The wild type $\mathrm{CDH} 1$ allele is missing in most lobular tumours due to loss of heterozygosity $(\mathrm{LOH})$ at chromosome 16q [8], thereby presenting a classical example of Knudson's two-hit hypothesis on the inactivation of tumour suppressor genes. The more frequent ductal breast carcinomas also show frequent $\mathrm{LOH}$ at $16 \mathrm{q}$; however, these tumours do not have mutational inactivation of the retained $\mathrm{CDH} 1$ allele [9]. Given the importance and widespread involvement of E-cadherin in tumorigenic processes, it is tempting to assume that a decrease in E-cadherin activity in ductal carcinomas is selected for and is reflected by $\mathrm{LOH}$ at $16 \mathrm{q}$. Indeed, haploinsufficiency has now been 
acknowledged as a true mechanism for tumour suppressor gene inactivation [10]. However, other genes at 16q could be targets of $\mathrm{LOH}$ in ductal tumours, justifying ongoing gene hunts.

\section{LOH at $\mathbf{1 6 q}$ in ductal and lobular breast cancer}

$\mathrm{LOH}$ at $16 \mathrm{q}$ is the second most frequent somatic genetic event in breast cancer. This event occurs in about $50 \%$ of all ductal carcinomas [11] and is slightly more frequent in lobular breast cancer [8]. To confirm E-cadherin as the target of LOH in ductal carcinoma, it is important to distinguish physical loss and mitotic recombination [12,13]. Only the first LOH event could theoretically lead to haploinsufficiency of $\mathrm{CDH}$. This seems unlikely, however, since there are so many complex mechanisms for regulation of $\mathrm{CDH} 1$ transcription that are often part of feedback loops [14]. Furthermore, our observations (unpublished data) on $\mathrm{LOH}$ at $16 \mathrm{q}$ in breast cancer indicate that both mechanisms for $\mathrm{LOH}$ are operative.

\section{E-cadherin protein expression in ductal and lobular breast cancer}

The complete absence of E-cadherin plasma membrane associated protein expression as detected by immunohistochemistry is so unambiguous that pathologists use this immunostaining to confirm their diagnosis of lobular breast cancer. We have stained a series of 86 breast carcinomas with known E-cadherin mutation status for E-cadherin protein expression [15]. Complete loss of protein was found in all lobular tumours with mutational inactivation of E-cadherin $(n=21)$. In addition, we were unable to detect E-cadherin in 11 lobular tumours in which no mutation had been identified. This is probably due to insensitivity of the mutation detection method or because other mechanisms of inactivation (e.g. methylation) were active. Remarkably, six cases of lobular breast cancer without a detectable E-cadherin mutation were positive for E-cadherin immunostaining. Of the 48 ductal breast cancers tested, $37 \%$ showed a decrease in but never a complete absence of $\mathrm{E}$-cadherin protein expression. If $\mathrm{E}$-cadherin was the target of $\mathrm{LOH}$ at $16 \mathrm{q}$ in ductal breast cancer, one would expect a strong association between $\mathrm{LOH}$ at $16 \mathrm{q}$ and decreased E-cadherin expression. However, the percentage of $\mathrm{LOH}$ at $16 \mathrm{q}$ in tumours with and without E-cadherin decrease was equal. It therefore seems unlikely that $\mathrm{LOH}$ at $16 \mathrm{q}$ is associated with a decrease in E-cadherin expression in ductal breast cancer. Also, in ductal carcinoma in situ (DCIS), there is no association between $\mathrm{LOH}$ at $16 \mathrm{q}$ and a decrease in E-cadherin expression. This can be derived from our combined data on $\mathrm{LOH}$ and E-cadherin immunohistochemistry, which was available for 62 cases of pure DCIS [16,17].

The adhesion function of E-cadherin is strongly indicative of a function in invasion suppression and this has indeed been shown in vitro [18] and in mouse models [19]. Investigation in primary tumours showed that this function translates well into metastatic potential [20]. There is no significant correlation between $\mathrm{LOH}$ at $16 \mathrm{q}$ in breast cancer and metastatic potential [11], however, which further contradicts an association between E-cadherin and $\mathrm{LOH}$ at $16 \mathrm{q}$.

\section{A breast cancer progression model}

The invasion suppressor function of E-cadherin is very obvious, but not in concordance with our earlier finding [16] that mutational inactivation of both $\mathrm{CDH} 1$ alleles through $\mathrm{LOH}$ and truncating mutations occurs in the preinvasive stage in lobular carcinoma in situ (LCIS), a tumour stage that involves proliferation but not dissemination. We showed that the same mutation and $\mathrm{LOH}$ at $16 q$ was present in the invasive tumour and the adjacent LCIS [16]. E-cadherin may thus play a role in invasive capacity, but more data suggest other signalling mechanisms may be involved in earlier tumorigenic processes, especially cellular proliferation. Indeed, E-cadherin is implicated in several signalling pathways: Wnt, Rho/Rac and p27 Kip1, which are involved in transcriptional activation, actin cytoskeleton reorganisation and contact inhibition, respectively [14].

$\mathrm{LOH}$ at $16 \mathrm{q}$ also occurs in the preinvasive stage, predominantly in grade I DCIS and in LCIS $[17,21]$. These observations and data in the literature led to a progression model of breast cancer (Fig. 1) based on early genetic alterations [17]. A similar multistep model for breast carcinogenesis has been proposed by Lakhani [22]. The model by Vos et al. [17] is less well defined than the Vogelstein model for colorectal cancer, because the latter is based on specific tumour stages and gene mutations. Similar stages are not defined for breast cancer and most of the genes involved are not yet identified. However, somatic genetic alterations in DCIS, LCIS and invasive carcinoma indicate that breast cancer progression is also based on the accumulation of genetic alterations. $\mathrm{LOH}$ at $16 q$ in grade I DCIS and LCIS led us to suggest that grade I DCIS may be a precursor for LCIS. Loss of E-cadherin further determines the histological fate of the tumour. Loss of chromosome $16 \mathrm{q}$ in grade I ductal and lobular breast cancer also lead Roylance et al. to speculate that these apparently morphological different tumours have a common molecular origin [23]. The observation of mixed populations of tumour cells, LCIS adjacent to DCIS, infiltrating lobular carcinoma and infiltrating ductal carcinoma (Fig. 2) supports this model, as well as investigations by Buerger et al. [24] on comparative genomic hybridisation of different tumour populations within the same lesion.

\section{E-cadherin germline mutations and lack of LOH in gastric cancer}

The identification of somatic E-cadherin mutations in breast and gastric cancer received less attention than 




Model of breast cancer progression. Grade II tumours are omitted for simplification. Two possible pathways may result in lobular carcinoma: 1, direct; or 2, via well-differentiated ductal carcinoma in situ (CIS). IDC, infiltrating ductal carcinoma; ILC, infiltrating lobular carcinoma; LOH, loss of heterozygosity.

Figure 2
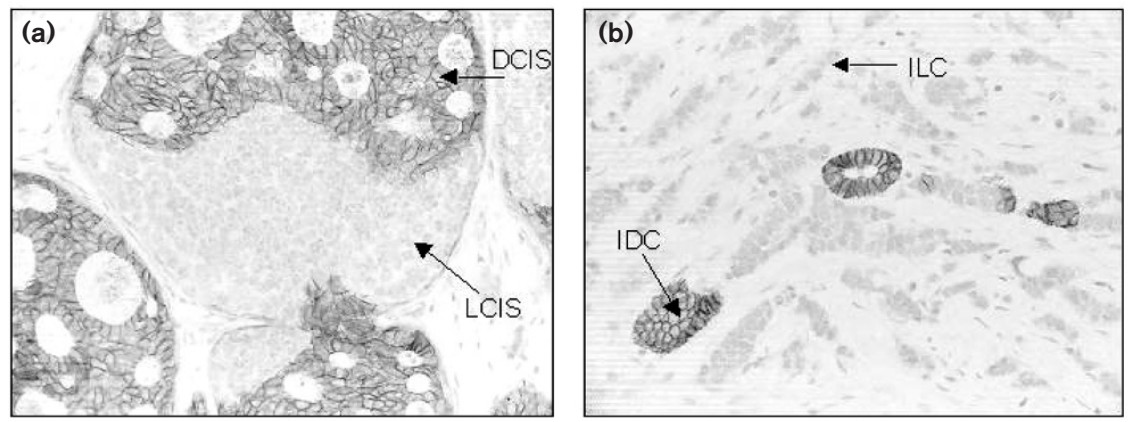

E-cadherin staining of mixed populations of (a) ductal carcinoma in situ (DCIS) and lobular carcinoma in situ (LCIS), and (b) infiltrating ductal carcinoma (IDC) and infiltrating lobular carcinoma (ILC). The E-cadherin staining was performed with antibody HECD-1 and distinguishes ductal from lobular tumour cells. Courtesy of Dr CBJ Vos.

the report on two Maori families with diffuse gastric cancer attributed to germline transmission of truncating mutations in $\mathrm{CDH} 1$ [25]. Although lobular breast cancer was expected, none was registered in these Maori families or in others reported on later [26]. Examination of $\mathrm{CDH} 1$ in 65 patients with LCIS revealed no germline mutations [27]. Loss of one $\mathrm{CDH} 1$ allele apparently gives an increased risk only for gastric cancer, both hereditary and sporadic.

Remarkably, at the level of $\mathrm{LOH}$, there is also a substantial difference between breast and gastric tumours. In diffuse gastric tumours, the wild type $\mathrm{CDH} 1$ allele is inactivated not by $\mathrm{LOH}$ at $16 \mathrm{q}$, but by promotor methylation [28]. This marked difference in general genetic mechanism may reflect a difference in the role of the tumour suppressor gene. Whereas the loss of E-cadherin is a rate-limiting factor in gastric cancer, in breast cancer it probably plays a role in a later stage and it determines the histological subtype.

\section{Conclusions}

$\mathrm{LOH}$ at chromosome arm $16 \mathrm{q}$ in breast cancer is a frequent event, occurring in at least $50 \%$ of breast cancer cases. In lobular breast cancer, a histological minority comprising $5-10 \%$ of all breast cancers, the E-cadherin gene is the target of this somatic genetic event. In ductal breast cancer it is unlikely that $\mathrm{CDH} 1$ is the target tumour suppressor gene, and other genes therefore remain to be identified. Classical LOH mapping efforts have not been successful in the identification of these target genes at chromosome 16 , or other genes in other tumour types, and we therefore need to apply different high-throughput screening methods to identify these remaining genes.

The E-cadherin gene has many different functions, even in carcinogenesis, given its involvement in early lesions and metastasis, hereditary and sporadic tumours, and numerous different tumour types. To elucidate whether this remarkable diversity indicates true separate activities or is a reflection of this protein's central role in cellular 
processes will be a challenging task for cellular biologists, geneticists and oncology researchers together.

\section{Acknowledgements}

The author wishes to acknowledge Dr CJ Cornelisse, Dr PCW Hogendoorn, and Dr MJ van de Vijver for helpful discussions, Dr C Vos for providing Figure 2, and Dr C Vos and Dr E Robanus Maandag for providing the data on DCIS immunohistochemistry.

\section{References}

1. Vleminckx K, Kemler R: Cadherins and tissue formation: integrating adhesion and signaling. Bioessays 1999, 21:211-220.

2. Yoshiura K, Kanai Y, Ochiai A, Shimoyama Y, Sugimura T, Hirohashi S: Silencing of the E-cadherin invasion-suppressor gene by $\mathrm{CpG}$ methylation in human carcinomas. Proc Natl Acad Sci USA 1995, 92:7416-7419.

3. Graff JR, Herman JG, Lapidus RG, Chopra H, Xu R, Jarrard DF, Isaacs WB, Pitha PM, Davidson NE, Baylin SB: E-cadherin expression is silenced by DNA hypermethylation in human breast and prostate carcinomas. Cancer Res 1995, 55:51955199.

4. Batlle E, Sancho E, Franci C, Dominguez D, Monfar M, Baulida J, Garcia DH: The transcription factor snail is a repressor of $\mathrm{E}$ cadherin gene expression in epithelial tumour cells. Nat Cell Biol 2000, 2:84-89.

5. Comijn J, Berx G, Vermassen P, Verschueren K, van Grunsven L, Bruyneel E, Mareel M, Huylebroeck D, Van Roy F: The twohanded $E$ box binding zinc finger protein SIP1 downregulates E-cadherin and induces invasion. Mol Cell 2001, 7:1267-1278.

6. Tan C, Costello P, Sanghera J, Dominguez D, Baulida J, De Herreros AG, Dedhar S: Inhibition of integrin linked kinase (ILK) suppresses beta-catenin-Lef/Tcf-dependent transcription and expression of the E-cadherin repressor, snail, in APC-/human colon carcinoma cells. Oncogene 2001, 20:133-140.

7. Berx G, Becker KF, Hofler H, Van Roy F: Mutations of the human E-cadherin (CDH1) gene. Hum Mutat 1998, 12:226237.

8. Berx G, Cleton-Jansen AM, Strumane K, De Leeuw WJF, Nollet F, Van Roy F, Cornelisse C: E-cadherin is inactivated in a majority of invasive human lobular breast cancers by truncation mutations throughout its extracellular domain. Oncogene 1996, 13: 1919-1925.

9. Berx G, Cleton-Jansen AM, Nollet F, De Leeuw WJF, Van de Vijver $\mathrm{MJ}$, Cornelisse $\mathrm{C}$, Van Roy F: E-cadherin is a tumour invasion suppressor gene mutated in human lobular breast cancers. EMBO J 1995, 14:6107-6115.

10. Jones PA, Laird PW: Cancer epigenetics comes of age. Nat Genet 1999, 21:163-167.

11. Cleton-Jansen AM, Callen DF, Seshadri R, Goldup S, McCallum $B$, Crawford J, Powell JA, Settasatian C, van Beerendonk H, Moerland EW, Smit VT, Harris WH, Millis R, Morgan NV, Barnes D, Mathew CG, Cornelisse CJ: Loss of heterozygosity mapping at chromosome arm 16q in 712 breast tumors reveals factors that influence delineation of candidate regions. Cancer Res 2001, 61:1171-1177.

12. Tischfield JA: Loss of heterozygosity or: how I learned to stop worrying and love mitotic recombination. Am J Hum Genet 1997, 61:995-999.

13. Devilee $P$ Cleton-Jansen AM Cornelisse CJ: Ever since Knudson. Trends Genet 2001, 17:569-573.

14. Beavon IR: Regulation of E-cadherin: does hypoxia initiate the metastatic cascade? Mol Pathol 1999, 52:179-188.

15. De Leeuw WJ, Berx G, Vos CB, Peterse JL, Van de Vijver MJ, Litvinov S, Van Roy F, Cornelisse CJ, Cleton-Jansen AM: Simultaneous loss of E-cadherin and catenins in invasive lobular breast cancer and lobular carcinoma in situ. J Pathol 1997, 183:404-411.

16. Vos CB, Cleton-Jansen AM, Berx G, De Leeuw WJ, ter Haar NT, Van Roy F, Cornelisse CJ, Peterse JL, Van de Vijver MJ: $\mathrm{E}$-cadherin inactivation in lobular carcinoma in situ of the breast: an early event in tumorigenesis. $\mathrm{Br} J$ Cancer 1997, 76:1131-1133.

17. Vos CBJ, ter Haar NT, Rosenberg C, Peterse JL, Cleton-Jansen A-M, Cornelisse CJ, Van de Vijver MJ: Genetic alterations on chromosome 16 and 17 are important features of ductal carcinoma in situ of the breast and are associated with histological type. Br J Cancer 1999, 81:1410-1418.

18. Vleminckx K, Vakaet L, Mareel M, Fiers W, Van Roy F: Genetic manipulations of E-cadherin expression by epithelial tumor cells reveals an invasion suppressor role. Cell 1991, 66:107119.

19. Perl AK, Wilgenbus $P$, Dahl U, Semb H, Christofori G: A causal role for E-cadherin in the transition from adenoma to carcinoma. Nature 1998, 392:190-193.

20. Birchmeier W, Behrens J: Cadherin expression in carcinomas: Role in the formation of cell junctions and the prevention of invasiveness. Biochim Biophys Acta 1994, 1198:11-26.

21. Lakhani SR, Collins N, Sloane JP, Stratton MR: Loss of heterozygosity in lobular carcinoma in situ of the breast. J Clin Pathol 1995, 48M:M74-M78.

22. Lakhani SR: The transition from hyperplasia to invasive carcinoma of the breast. J Pathol 1999, 187:272-278.

23. Roylance R, Gorman P, Harris W, Liebmann R, Barnes D, Hanby A, Sheer D: Comparative genomic hybridization of breast tumors stratified by histological grade reveals new insights into the biological progression of breast cancer. Cancer Res 1999, 59:1433-1436.

24. Buerger $H$, Simon $R$, Schafer KL, Diallo R, Littmann R, Poremba C, Van Diest PJ, Dockhorn-Dworniczak B, Bocker W: Genetic relation of lobular carcinoma in situ, ductal carcinoma in situ, and associated invasive carcinoma of the breast. Mol Pathol 2000, 53:118-121.

25. Guilford $P$, Hopkins J, Harraway J, McLeod M, McLeod N, Harawira P, Taite H, Scoular R, Miller A, Reeve AE: E-cadherin germline mutations in familial gastric cancer. Nature 1998, 392:402-405.

26. Richards FM, McKee SA, Rajpar MH, Cole TR, Evans DG, Jankowski JA, McKeown C, Sanders DS, Maher ER: Germline Ecadherin gene $(\mathrm{CDH} 1)$ mutations predispose to familial gastric cancer and colorectal cancer. Hum Mol Genet 1999, 8:607-610.

27. Rahman N, Stone JG, Coleman G, Gusterson B, Seal S, Marossy A, Lakhani SR, Ward A, Nash A, McKinna A, A'Hern R, Stratton MR, Houlston RS: Lobular carcinoma in situ of the breast is not caused by constitutional mutations in the E-cadherin gene. Br J Cancer 2000, 82:568-570.

28. Grady WM, Willis J, Guilford PJ, Dunbier AK, Toro TT, Lynch H, Wiesner G, Ferguson K, Eng C, Park JG, Kim SJ, Markowitz S: Methylation of the CDH1 promoter as the second genetic hit in hereditary diffuse gastric cancer. Nat Genet 2000, 26:16-17. 